\title{
1 A Building Information Modelling approach to the alignment of organisational \\ 2 objectives to asset information requirements
}

\section{Abstract}

4 It is critical that an asset-centric organisation understand the importance of their engineered assets to operate successfully. Despite this, organisations struggle to view assets within the context of whole-

6 life management and ultimately struggle to harness the full potential value. A recurring theme is the challenges in capturing, storing and validating data across a diverse and complex asset portfolio. The primary reason for this is the fundamental lack of understanding of what information should be collected to support the efficient management of assets throughout their life. Asset-related information that is not collected in alignment to the organisational requirements will restrict the performance of capital investment decisions, risk management and operational performance throughout the whole life of the asset portfolio and ultimately have an impact on productivity. This paper presents a top-down methodology that utilises Building Information Modelling to support the development of asset Information Requirements, the novel aspect of this approach is the development of Functional Information Requirements to bridge the gap between organisational requirements and asset information requirements.

17 Keywords

Requirements, Organisational Information Requirements, Asset Information Requirements, Requirements Engineering

\section{Introduction}

The importance of information management within the whole-life cycle of engineered assets is gaining momentum both in academic literature and industrial applications. Information management within the domain of Engineering Asset Management (EAM) is being guided by a set of industry specifications and standards that are solely focused on information management processes for the individual lifecycle phases (design, construction, Operations and Maintenance (O\&M) and disposal / renewal) of engineered assets [1-3]. Most notable is the adoption of Building Information Modelling (BIM) that has seen a step change in how information is managed during the design and construction phases, with 
widespread evidence demonstrating a reduction in design and construction cost, increase in productivity and improved risk management [4-6]. Despite this, it can be seen that the adoption of BIM within the O\&M phase is relatively limited [7]. The complexity of adopting BIM within the O\&M is multi-pronged, common BIM information management challenges highlighted within the literature are summaries below:

1. Fundamental lack in understanding how to demonstrate the value of BIM within the operational requirements. [7].

2. Historically the O\&M industry has been hesitant to adopted new and emerging technology processes,

4. O\&M personnel are rarely consulted on their requirements for a BIM-enabled project, this results in a BIM model that is not optimised for O\&M [13].

A recurring theme is a fundamental challenge in demonstrating the value of BIM within the operational requirements of an organisation [7]. This is partly because asset owners, operators and maintainers fail to identify Asset Information Requirements (AIR) during the early BIM development stages, that leads the development of BIM processes that generate little value for the organisation. Organisational Information Requirements (OIR), if developed at all, are generally in the form of technical documentation and do not consider the organisational context within their development. Using these challenges as a foundation the following research questions has been developed to aid this research effort 1) how can the domains of BIM, Asset Management and Requirements Engineering be aligned to aid the development of organisation-lead Asset Information Requirements? This leads to a sub question of 2) How can the use of BIM-enabled asset classification system provide support to bridge the gap between organisational objectives, Organisational Information Requirements and Asset Information Requirements? 
This paper investigates the development of organisational led AIR that supports BIM enabled processes within the O\&M lifecycle phase of engineering assets. An extension of the current BIM information management relationship framework as defined within PAS 1192-3:2014 [14] is proposed. To support the development of AIR's that is generated from OIR's, an intermediate step that utilises the organisational point-of-view of engineering assets is required - the development of Functional Information Requirements (FIR).

The paper is organised as follows. Section 2 provides a review of academic literature and industry standards and specifications in the domain of BIM and EAM. Section 3 introduces the information requirements alignment methodology. Section 4 provides an overview of the methodology within two industry case studies. Finally, Section 5 summaries the key finds and challenges, proposing future research opportunities.

\section{Background}

With the rapid development of computing power in the 1950 s and '60s, organisations found themselves with enormous and promised opportunities to streamline business processes and systems while also gaining greater insight and control. With this rapid development, there was a need to understand the user requirements of these new semi-automated Information Management Systems (IMS). It was quickly realised that you simply could not ask managers what information they require, as they operate in specific organisational functions and give bias to their priorities [15]. It is a mistake to assume that managers know what information they require and that this information will aid them in making better decisions, while evidence demonstrates the contrary [16]. Newly implemented IMS often require significant revisions to meet even the simplest of information requirements to support management decisions [17]. This often has a fiscal impact, with redesigning cost and time being significantly higher than the initial cost, in some cases as much as 50 to 100 times higher [15]. Information requirements do not arise naturally and therefore have to be engineered, highlighting the need for improving techniques in the development of information requirements to meet this significant challenge [18].

84 There is a growing set of methodologies, frameworks and tools to address the challenge of 85 developing information requirements within an IMS. Some well documented techniques include 
87 21]. These techniques were the result of extensive research efforts in the early 1980s and ' 90 s that sought to solve the problems of developing information requirements.

\subsection{Requirement Engineering}

As IMS became increasingly popular, there has been a shift from process driven techniques to usercentric design that requires a thorough understanding of the needs and requirements of the users for designing an IMS [22]. The process of developing user requirements has manifested itself as a research and industry domain known as Requirement Engineering (RE).

$\mathrm{RE}$ is commonly referred to as a branch of software engineering that is concerned with the real-world wants and requirements for the design, development and implementation of information management solutions, e.g. software development [23]. The RE process consists of 5 main activities: eliciting requirements, modelling and analysing requirements, communicating / documenting requirements, agreeing on requirement and management of requirements [24]. There are many techniques available for the individual stages to ensure that the requirements are complete, relevant and consistent. These include stakeholder engagement [25], requirements prioritisation [26], storyboarding [27] and configuration management [28].

RE has predominantly been implemented within none asset-centric organisations such as financial firms, communication firms and marketing, with limited implementation in asset-heavy industries such as rail, highways and estate management. This is partly due to the late and poor adoption of IMS within the engineering industry.

\subsection{Information Management Within Engineering Asset Management (EAM)}

EAM involves the management of engineering assets throughout their whole-life, which involves the management of cost, risk and opportunities against the desired performance of the assets, to achieve the organisational requirements [1]. An asset (or engineered asset) within the domain of EAM is a physical asset (such as a bridge or rail signal) or an intangible assets (such as people or data its self) that has potential or actual value to an organisation $[29,30]$. The scope of this paper is focusing on the physical / engineered assets. EAM has an emerging domain of research within information management noted as one of the key challenges and enablers of supporting efficient development, implementation and operating of an EAM system [31]. Furthermore, a series of standards were developed by the ISO to outline a methodology for the design, development and implementation of an 
116 EAM system [1-3]. This includes the development and documentation of EAM objectives, plans and

117 requirements.

118 BIM has been widely cited as an enabler to supporting the development of information management 119 processes within EAM, most notably supporting the exchange of information throughout the lifecycle of an asset and supporting the development of information requirements [32]. BIM is the process of

121 designing, constructing or operating a building or infrastructure asset using object-oriented design

122 [33]. The British Standards Institute (BSI) has developed an array of BIM related specifications and

123 standards for an asset's lifecycle management including the exchange of information (geometry and non-geometry), information management processes, common data environment and level of detail [14,33-37]. Most notably, PAS 1192-3:2014 aims to provide a specification for information management within the operational phase of assets [14]. One of the critical components within the specification is defining the relationship between elements in the management of information. Figure information requirements developed within a BIM-enabled organisation.

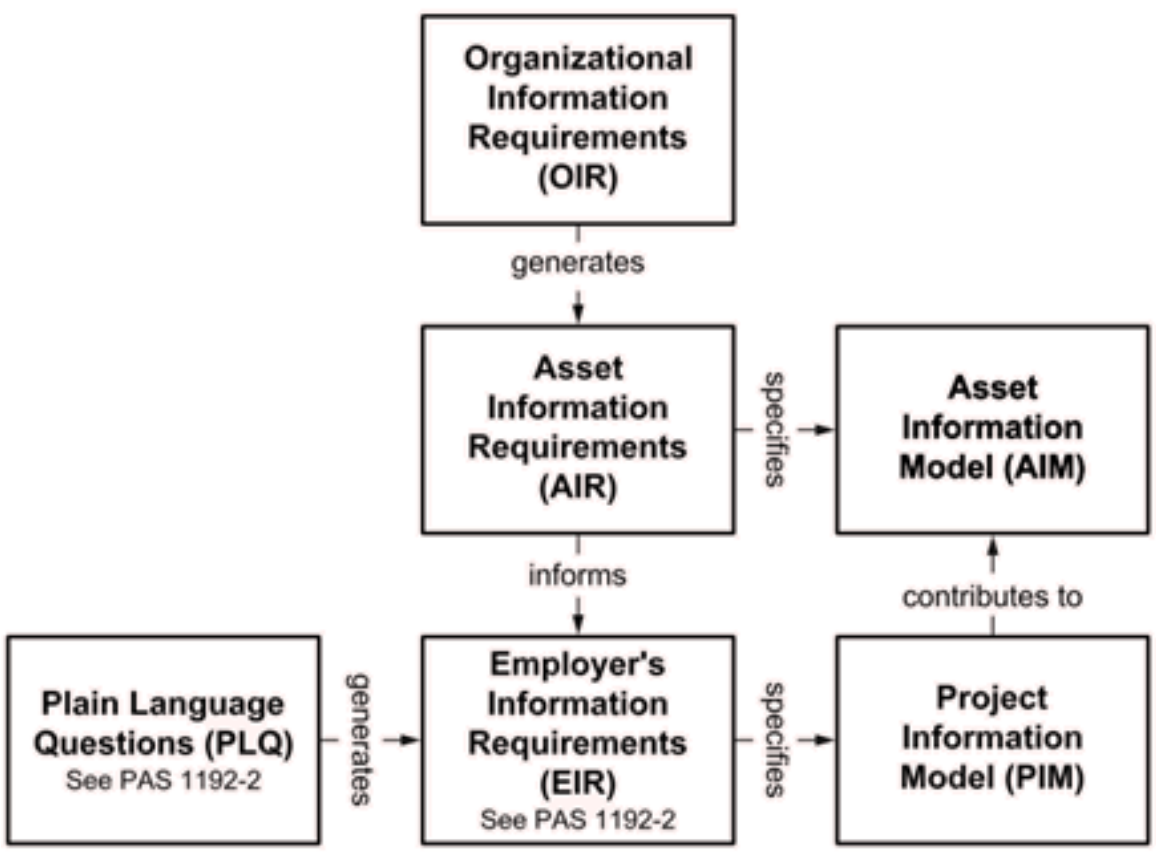

132 The purpose of the Asset Information Model (AIM) is to be a sole source of validated and approved 133 information related to specific assets. The development of Organisational Information Requirements 134 (OIR) which helps generate Asset Information Requirements (AIR) is a complex task, with very few 
examples of this being implemented in practice $[38,39]$. OIR and AIR development is led by technical guidelines, codes, regulations and specifications and will, therefore, struggle to meet the commercial,

137 financial, managerial and customer management requirements of the organisation. Therefore it is critical that a systematic approach is used for developing the OIR from the stakeholders (e.g., clients, operators) requirements [40].

140 The Employers Information Requirements (EIR) is developed when the organisation requires

141 information from the contractors of capital works projects. It supports the procurement of information

142 as per the organisational requirements. There are limited examples in the academic literature that

143 focus on the development of specific elements of this framework. Cavka [41] proposes a four-step

144 methodology for the development of owners information requirements and how they related to BIM.

145 This includes: (i) identify sources \& collect data, (ii) classify landscape of owner requirements, (iii)

146 identify the required information, and (iv) relate digital information with physical product requirements.

147 While this is a comprehensive methodology, it does not create an alignment between the

148 organisational requirements and specific AIR. Ashworth [39] argues that the OIR and AIR should be

149 developed by facility managers and asset managers as they are uniquely placed to understand the 150 organisational requirements of their assets. He further proposes an engagement model for their 151 involvement. While nobody would argue that facility managers and asset managers should be 152 consulted within developing the OIR and AIR, the bulk of their knowledge would be within the 153 technical operational requirements. Using their perspective above others would risk missing 154 alternative organisation requirements such as commercial, financial, managerial and customer. 155 Finally, Patacas [42] proposes using the Information Delivery Manual (IDM) methodology developed 156 by BuildingSMART [43] and developed into an ISO Standard [44,45]. IDM uses the concept of 157 process maps defined in Business Process Modelling Notation (BPMN), highlighting the flow of 158 information, models and data between different stakeholders over a set of lifecycle stages for a 159 specific activity while the IDM methodology supports the required integration between stakeholders 160 and lifecycle stages, being activity driven risks missing the organisational requirements that are not 161 explicitly known for a given activity. 
2.3 Standards to Support Information Management Processes within Engineering Asset Management

As stated above there are several specific standards related to BIM information management processes and EAM. Furthermore, there are several standards that are not directly related to BIM or EAM but indirectly support the design, development and governance of information management processes within EAM. ISO 12006-2 provides a classification system for both the construction and EAM industry [46]. This includes classification of activities such as painting and classification of engineering assets such as a window, beam or ventilation systems. This standard provides a consistent approach to the classification of construction and EAM related objects. Therefore, it supports the exchange of information between an asset's lifecycle and between the many stakeholders. ISO 12006-3 consists of a taxonomy model which can be used to develop dictionaries and relationships to store or provide information related to construction works [47]. BS 8536-1/2 gives recommendations for briefing the design and construction personnel to ensure that they consider the assets performance requirements throughout its operational life, e.g. considering the operational requirements at the very earliest design stages [48,49]. Finally, Government Soft Landings (GSL) is a

177 framework for delivering pre-defined sets of information during the design and construction lifecycle,

178 supporting a structured transfer into the operational phase [50].

\subsection{Summary}

180 From the earliest developments of IMS, developing the information requirements for those systems is 181 a complex and puzzling task that is often neglected and result in reduced operational performance.

182 Furthermore, the adoption of IMS within EAM is immature compared to other domains. While a 183 branch of software engineering called Requirements Engineering (RE) has provided a framework for 184 the development of information requirements, the conventional techniques used within the framework 185 have limited use within EAM due to its multifaceted nature. Most notably, RE fails to address the 186 whole-life management requirements of EAM. BIM has been described as a critical enabler for the 187 adoption of an IMS within the construction and EAM sectors. While BIM has been actively 188 implemented within the design and construction phases, it adoption within the operational phase has 189 been limited. This is partly due to the complexity of capturing OIR within the initial stages of the BIM 190 information management processes. While there are a few example methodologies in the literature, 191 they use the current approach of assuming that the OIR can directly create the AIR, but it can be 
192

witnessed that the jump from OIR to AIR is a challenging step for most organisations. The reasons for this challenge are multifaceted and summarised below:

1. Organisational management team often don't understand the technical aspects of the assets they maintain and operate.

2. Organisational requirements are often abstract and therefore poorly translate directly into AIR.

3. Due to management teams challenge to develop information requirements, AIR are developed from a technical perspective and lacking basic information for management processes such as financial management and risk management.

These challenges are addressed by utilising the methodology proposed in this paper, adding the intermediate step of defining FIR's.

\section{Information Requirements Development Methodology}

As highlighted within section 2, there is a clear knowledge gap within the development of OIR within the domain of EAM. Furthermore, it can be observed that generating the AIR from the OIR is too much of a leap for most organisations and that a more comprehensive framework is required to aid in bridging this gap. This section proposes a systematic methodology to generate Asset Information Requirements ensuring alignment with organisational requirements. This is enabled by an intermediate step of Functional Information Requirements (FIR) which utilises the organisational point-of-view of the assets as the functional output that they support. Figure 2 illustrates the extension, and the dotted lines demonstrate a validation process that ensures the resulting Asset Information Model align with the OIR. This methodology takes a specific UK perspective of BIM due to the use of British developed standards and specifications, specifically the BS/PAS 1192 series. While this is currently true, there are several working groups within ISO that aims are to develop the British standards into international ISO standards, which would support the applicability of this methodology outside of the UK [51]. Furthermore, the ISO 55000 on Asset Management Systems is an international standard and the concepts of BIM and RE have been widely adopted to a degree within many countries that align their adoption in part or full to the proposed methodology. 


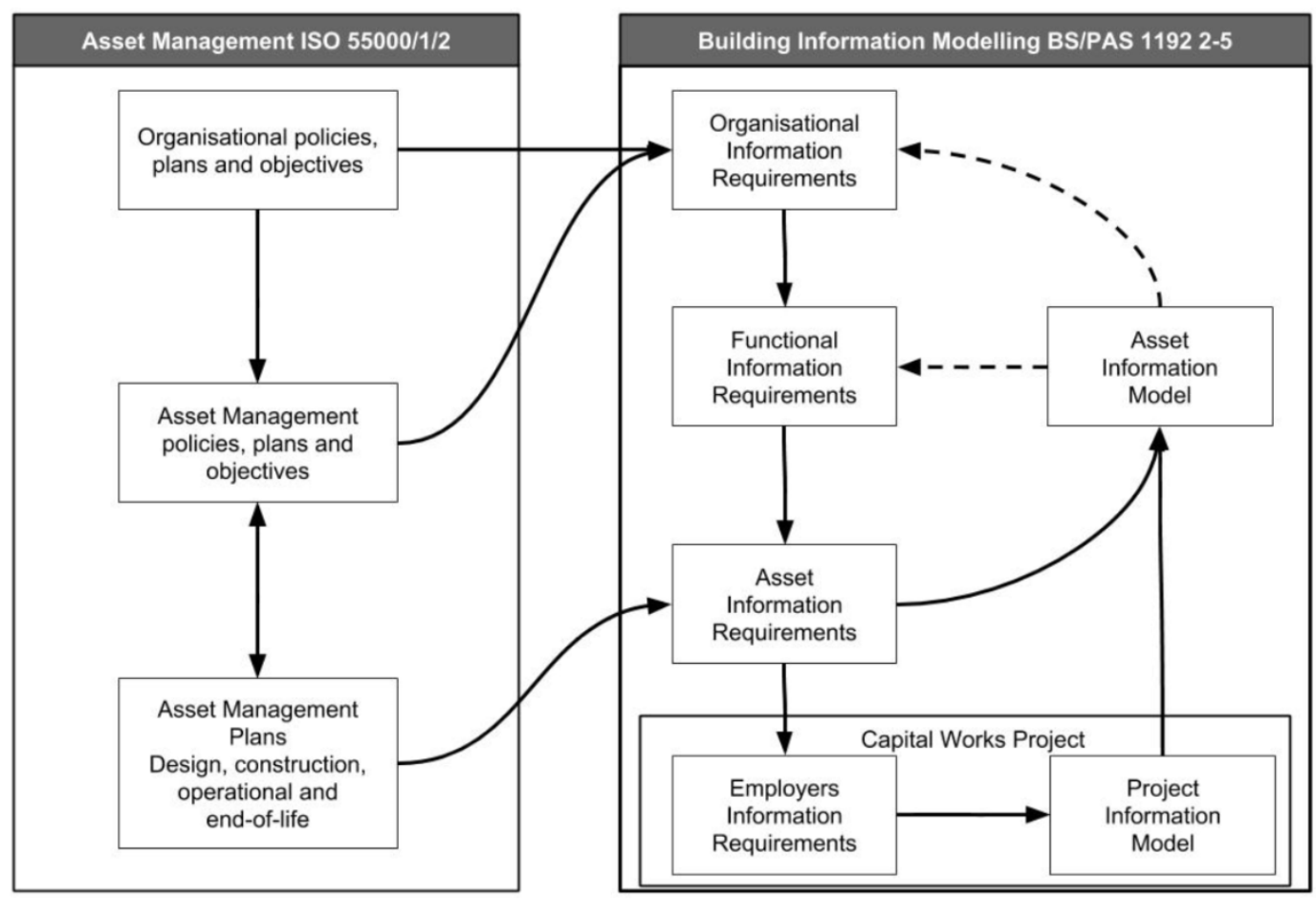

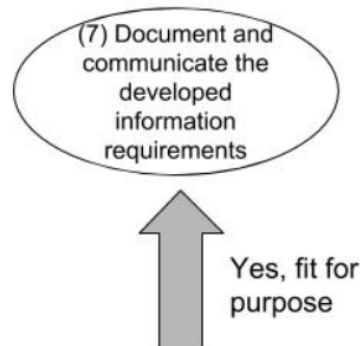

(6) Validate the

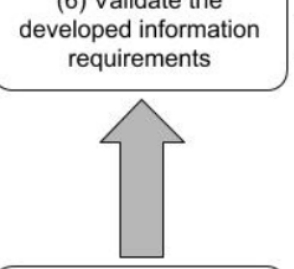

(5) Develop Asse Information Requirements

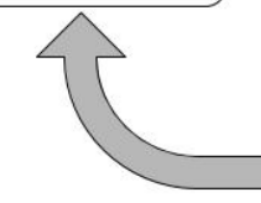

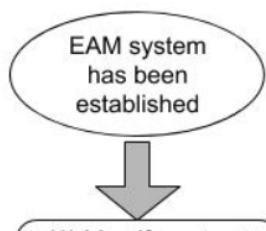

(1) Identify, extract and categorise organisational requirements
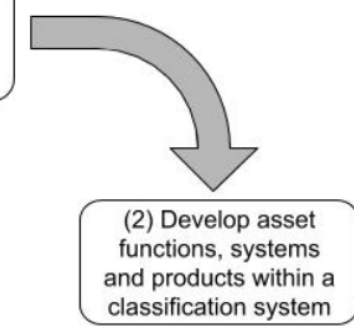

No, requires review

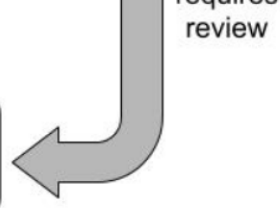

4) Develop

Functional Information Requirements 
223 A seven-stage step methodology is proposed that aids in the development of information

224 requirements, which is illustrated in Figure 3 and will now be described in detail.

\section{Step 1 - Identify, extract and categorise organisational objectives}

226 The first task is to identify the organisational and EAM objectives, Depending on the size and context of the organisation, these can be spread over several documents often developed in isolation within individual departments. The set of documentation that should be analysed includes annual reports, environmental impact strategy, customer strategy and financial growth reports. Analysing the documents involves comprehensibly reviewing the documents and extracting the objectives within them. Care should be taken to extract SMART ${ }^{1}$ objectives, where available. Some documentation list objectives within a separate section, while other documents have objects embedded into the broader text, hence why the documents require a comprehensive review. Finally, if the text is not clearly stated as an objective, then it should be validated with the author / business owner to ensure that it is an objective. If the organisation has developed an EAM system as defined within the ISO 55000 standards [1], the documents produced to develop such a system including asset management policies, asset management plans and objectives should be prioritised for analysing. Furthermore, BIM related documentation such as Information Management Processes (IPM), Employers Information Requirements (EIR) and BIM data security strategy should also be analysed, to captures

240 BIM related objectives. A common set of organisational documents that should be analysed are summarised in Table 1. If necessary, the objectives can also be identified through targeted interviews

242 with key decision makers within the organisation. Where interviews are used to capture the objectives, care should be taken to ensure that personal biases of the interviewees are avoided

244 through useful triangulation. If the organisation has developed a balanced scorecard, this can be a valuable tool to extract non-financial performance measures and objectives [52].

Source of Objectives

Strategic Asset

Management Plan

(SMAP)
Description Key strategic documentation as part of ISO 55000, contains asset management objectives, goals and plans that align with organisational objectives.

Objectives

Operational objectives
Financial objectives
Training objectives
HR objectives
ealth \& Safety objectives

\footnotetext{
${ }^{1}$ specific, measurable, attainable, relevant, and time-bound (SMART)
} 


\begin{tabular}{|c|c|c|}
\hline Environmental Strategy & $\begin{array}{c}\text { Contains an organisational environmental framework and } \\
\text { objectives to minus the impact of the organisation's } \\
\text { requirements on the natural environment }\end{array}$ & $\begin{array}{l}\text { Environmental objectives } \\
\text { Air pollution reduction } \\
\text { objectives }\end{array}$ \\
\hline $\begin{array}{l}\text { Customer Engagement } \\
\text { Strategy }\end{array}$ & $\begin{array}{l}\text { Provides a framework and objectives for engagement with } \\
\text { customers and end-users. Often contains engagement } \\
\text { targets and customer satisfaction targets }\end{array}$ & $\begin{array}{l}\text { Reputational objectives } \\
\text { Customer objectives }\end{array}$ \\
\hline $\begin{array}{l}\text { Financial Growth Strategy } \\
\qquad \text { (Business Plan) }\end{array}$ & $\begin{array}{l}\text { A strategic document that outlines the organisation finical } \\
\text { growth plans and objectives. }\end{array}$ & $\begin{array}{l}\text { Financial objectives } \\
\text { Growth objectives }\end{array}$ \\
\hline $\begin{array}{l}\text { Information/Technology } \\
\text { Strategy }\end{array}$ & $\begin{array}{l}\text { Provides a framework and objectives for the } \\
\text { implementation of technology and information management } \\
\text { systems. }\end{array}$ & $\begin{array}{c}\text { Data management objectives } \\
\text { Digital adoption objecitves }\end{array}$ \\
\hline BIM Execution Plan & $\begin{array}{c}\text { contains BIM related requirements and objectives, most } \\
\text { notably for the design and construction phase but could be } \\
\text { utilised within the operational phase. }\end{array}$ & $\begin{array}{l}\text { Data management objectives } \\
\qquad \text { BIM target objectives }\end{array}$ \\
\hline
\end{tabular}

247 After reviewing the documentation described within this section, it can be witnessed that there are six

248 individual categories that all objectives can be categorised within, independent of the services or

249 produces that the organisation provides. This is partly due to the board nature of the categories

250 themselves and individual organisations following common management processes such as quality,

251 risk and fiscal management and producing similar documentation as an outcome. Therefore, the

252 objectives identified within this section should be categories within a single category of financial,

253 environmental, operational, customer, health and safety and reputational. Categorising the objectives

254 is especially important for four reasons:

255 (i) Large organisations could have over a hundred requirements, and analysing these

256 requirements is made simpler by categorising them.

257 (ii) The categorisation can help identify any gaps within a specific category.

258 (iii) It allows for identifying conflicting or duplicate organisational requirements.

259 (iv) It helps to identify a baseline of universal information requirements that are required for

260 different organisational requirements within the same category, therefore reducing

261 duplication of work and provide a foundation for more specific information requirements.

262 The outcome of this first step is a comprehensive set of organisational objectives that form the

263 foundation for consolidation into a clear set of OIR.

264 Step 2 - Develop asset functions, systems and products within a classification system 
265 The second step requires the organisation to classify its asset portfolio using an asset classification

266 system. An organisation classifying it engineering assets is a crucial element of the methodology as it

267 supports the future development of information requirements. The parent-child Hierarchy relationship

268 within the classification systems is utilised to support the developed multiple levels of information

269 requirements, from high-level requirements (e.g. heating or ventilation requirements) to low-level

270 granular requirements (e.g. radiator or air supply fan). The most comprehensive classification systems

271 that support EAM are UNIClass and Omniclass [53,54]. They both follow the industry standard ISO

272 12006-2 [46] for classification of assets.

273 Traditionally classification systems are implemented by looking at the individual assets themselves

274 and not the asset systems or functions that they support. This can be a daunting task, as even small

275 organisations can have different individual assets that number in the thousands. Furthermore, these

276 risks alienating the departments of the organisation that do not focus on the performance of individual

277 assets but the functional output that they support, such as the financial or human resources

278 departments. Figure 4 demonstrates the parent-child relationship as defined within ISO 12006-2 with

279 examples of definitions from UNIClass, this section describes how such an approach can be utilised

280 to aid in the development of information requirements. 


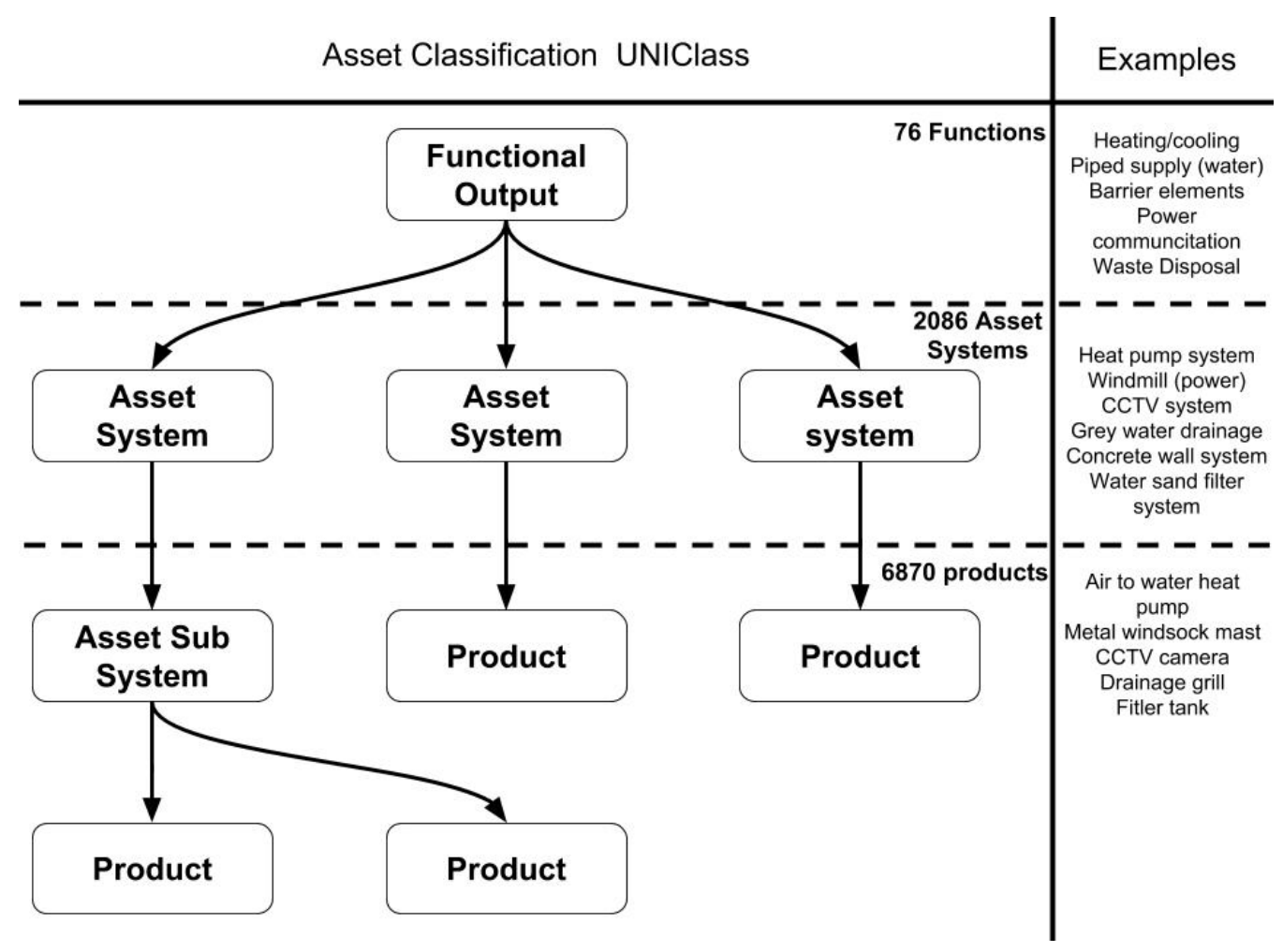

283 It is proposed when implementing a classification system that the organisation first classify the

284 functional output of their engineering assets. UNIClass Table EF provides a database of 76 functions

285 that offers a comprehensive set of functional output covering all sectors including infrastructure,

286 buildings and civil works. The key benefit of such a classification system is having a starting point for

287 engineering asset classification that is understood through different organisational departments. As an

288 example, the customer relationship department within an estate management company won't have

289 expert knowledge on the engineering asset systems or products that support the function of heating,

290 but they will understand the performance requirements (e.g. temperature) that the tenants require.

291 Furthermore, classifying the assets functional output enables the alignment of the functional output to

292 the asset systems and the products that support that system, this creates a direct line-of-sight from

293 the asset functional output to the asset systems and products. Moving down the classification

294 hierarchy, it is then required to classify the asset systems that support the funcational output.

295 UNIClass Table Ss provides a classification of 2085 asset system. Only asset systems that support

296 the functional output should be classified. A sub-system might be required to be classified depending

297 on the specific organisational requirements. Finally, the lowest level of the engineering asset

298 classification system is the individual products that support the asset systems. UNIClass $\operatorname{Table} \operatorname{Pr}$ 
provides a classification of 6870 products. Care should be taken when classifying products, as

300 classifying all the products within the asset systems can be an extensive task, only products that are

301 critical to the organisational objectives should be classified.

302 The critical outcome of this step is to have implemented a comprehensive classification system of the organisation's engineering assets. The classification should start at the highest level of the assets

304 functional output, as this is how an organisation views the performance of its engineering assets. The classification system is used within the following steps to support the developing of the information requirements.

\section{Step 3 - Develop Organisational Information Requirements (OIR) that Align to the}

309 The third step is to translate the individual organisational objectives into an OIR. The primary goal of 310 developing an OIR is to provide the information that is required to inform the performance of meeting

311 (or not) the organisational objectives identified in step 1. The OIR should aim to meet all the requirements of an EAM system and organisational departments. The development of an OIR can be

313 a daunting and complicated task due to its broad and cross-department nature. To provide a starting

314 point in the OIR development, three categories are used to classify the captured information

315 requirements within financial, managerial and technical, a summary of these is provided in Table 2.

\begin{tabular}{|c|c|}
\hline Information Requirement Category & Summary \\
\hline Financial information requirements & $\begin{array}{l}\text { Financial information requirements capture related financial information that } \\
\text { supports the monitoring and validation of financial related performance and } \\
\text { support such functions as whole-life costing, capital investment plans and } \\
\text { strategic financial decision-making processes. Examples of financial } \\
\text { information include operational cost, maintenance cost and initial cost. }\end{array}$ \\
\hline Managerial information requirements & $\begin{array}{l}\text { Managerial information requirements capture managerial information that an } \\
\text { organisational requires to maintain their assets, including legal and } \\
\text { commercial elements efficiently. Examples of managerial information include } \\
\text { ownership, asset location and warranty / insurance information. }\end{array}$ \\
\hline Technical information requirements & $\begin{array}{l}\text { Technical information requirements capture information that an organisation } \\
\text { requires to evaluate design, operational and maintenance performance limits } \\
\text { of their assets. Example of technical information includes operational }\end{array}$ \\
\hline
\end{tabular}


317 While the identified information categories support the management and classification of information

318 requirements, they don't directly support their development. Supporting the development of

319 information requirements, we utilise two methodologies firstly, Critical Success Factors (CSF) from the

320 domain of requirements engineering and Plain Language Questions (PLQ's) from the domain of BIM.

321 CSF has been Widely used within the domain of requirements engineering to highlight a customer

322 and end-user requirements for the development of IMS. CSF forces managers to ask the question,

323 what are the critical success factors of the business department I manage? And what information is

324 required to ensure the critical success factors are acceptably managed? This approach is slightly

325 modified to move focus away from individual organisational departments to organisational objectives

326 by changing the question to, what are the critical success factors of achieving this objective? The CSF

327 acts as guidance and provides a structured approach to the development of PLQ's. PLQ's form part of

328 the BIM information requirements development process as outlined within PAS 1192-3 [14]. PLQ's

329 are designed as a way for clients and end-user to communicate their broad and complex information

330 requirements within a set of simple understandable questions. PLQ's within the contents of this

331 approach is utilised to aid in the development of OIR, by developing high-level questions that an

332 organisation need to be answered to confirm if they are meeting (or not) their objectives. The data to

333 answer these questions will be found in the organisation's engineering assets, the questions are

334 summarised into a set of information requirements. lastly, the data type (string, integer, date/time and

335 Boolean) of the data required to answer the question is identified. Table 3, shows an example of

336 organisational objectives and associated CSF, PLQ's and data type.

Reduce the Total Business Impact of Estate Facilities' Controllable Costs by $5 \%$

\begin{tabular}{c|c|c|c}
$\begin{array}{c}\text { Critical Success } \\
\text { Factors }\end{array}$ & Category & Question & $\begin{array}{c}\text { Data } \\
\text { Information Requirement }\end{array}$ \\
\hline $\begin{array}{c}\text { prompt response } \\
\text { to maintenance } \\
\text { requirements }\end{array}$ & Operational & $\begin{array}{c}\text { What is the current response } \\
\text { time to maintenance request? }\end{array}$ & <current_responce_time> \\
& $\begin{array}{c}\text { What is the cost savings to a } \\
\text { prompt response to maintenance } \\
\end{array}$ & requests?
\end{tabular}




\begin{tabular}{|c|c|c|c|c|}
\hline & & $\begin{array}{l}\text { what is the desired response } \\
\text { time to maintenance request? }\end{array}$ & $<$ desired_responce_time $>$ & Integer \\
\hline & & $\begin{array}{c}\text { who is reasonable for planning } \\
\text { maintenance? }\end{array}$ & <planning_maintenance_owner> & String \\
\hline \multirow[t]{3}{*}{$\begin{array}{c}\text { reduction in } \\
\text { operational cost }\end{array}$} & \multirow[t]{3}{*}{ Financial } & $\begin{array}{c}\text { What is the current total } \\
\text { operational cost? }\end{array}$ & <total_operational_cost> & Integer \\
\hline & & $\begin{array}{c}\text { what is the difference between } \\
\text { the planned operational cost and } \\
\text { the current? }\end{array}$ & $<$ current_vs_planned_operational_cost> & Integer \\
\hline & & $\begin{array}{c}\text { who is reasonable for the } \\
\text { operational cost? }\end{array}$ & $<o p e r a t i o n a l \_c o s t \_o w n e r>$ & String \\
\hline \multirow[t]{3}{*}{$\begin{array}{l}\text { reduction in } \\
\text { maintenance } \\
\text { costs }\end{array}$} & \multirow[t]{3}{*}{ Financial } & $\begin{array}{l}\text { what does the total maintenance } \\
\text { cost? }\end{array}$ & $<$ total_main_cost> & Integer \\
\hline & & $\begin{array}{l}\text { what is the planned maintenance } \\
\text { costs? }\end{array}$ & <planned_main_cost> & Integer \\
\hline & & $\begin{array}{c}\text { what is the difference between } \\
\text { the planned maintenance cost } \\
\text { and the current? }\end{array}$ & <planned_vs_current_main_cost> & Integer \\
\hline \multirow[t]{3}{*}{$\begin{array}{c}\text { less reactive } \\
\text { maintenance and } \\
\text { more planned } \\
\text { maintenance }\end{array}$} & \multirow[t]{3}{*}{ Operational } & $\begin{array}{c}\text { what is the total reactive } \\
\text { maintenance requests to date? }\end{array}$ & $<$ reactive_main_request $>$ & Integer \\
\hline & & $\begin{array}{c}\text { what is the total planned } \\
\text { maintenance to date? }\end{array}$ & <planned_main_instances> & Date \\
\hline & & $\begin{array}{c}\text { what is the difference between } \\
\text { reactive and planned } \\
\text { maintenance? }\end{array}$ & $<$ planned_vs_reactive_main $>$ & String \\
\hline
\end{tabular}

339 The final exercise in this step is to align the organisational objectives with the functional asset outputs

340 defined within step 2 . This is achieved by ranking the top three functions within the organisation's

341 engineered assets that will have the most significant impact on achieving (or not) the organisational

342 objective. For example, a financial objective will be the top functions which the most expenses or

343 revenue generating functions to operate and maintain. While an environmental related objective

344 would focus on the highest polluting functions, asset managers and asset maintainers should be

345 consulted to ensure that the most relevant functions are selected and ranked correctly, as the ranking

346 of the functions is a subjective task, it is critical to have the appropriate people in the room. These

347 functions will be used within the following steps to translate the OIR into FIR and AIR.

348 The critical outcome of this step is a comprehensive set of OIR per organisational objective, this is

349 supported by the development of CSF and PLQ. the OIR's focus on the information required by the

350 organisation to achieve (or not) its objectives. Simply put, the OIR's developed should be a set of 
questions that an organisation asks of their engineering assets, the data received will aid in answering the questions. Furthermore, the top three asset functions that impact the objectives are captured and used in the following steps.

\section{Step 4 - Develop Functional Information Requirements (FIR)}

355 The fourth step is to define the FIR for the functional outputs as captured within step 3 . The definition of an FIR is "information requirements developed at an asset's functional output level of an organisations asset classification system that support the organisational requirements of their assets, including asset management, whole-life cycle costing and capital investment decisions".

This should aim to answer the questions asked in the OIR at a functional output level. When developing FIR's it is critical to not jump to the asset system or product level, as which is common within asset centric organisations. Care should be taken to enforce the point that we are capturing the impact of the asset functional output on the organisational objective. As an example, we want to understand how the functional output of heating can have an impact on the objective to reduce operational cost and what specific information is required from the function of heating to achieve this objective. As stated within step 1 the advantages of classifying engineering assets by their functional output is creating an alignment between the organisation and their assets they maintain and operate, the information captured within the FIR will aid in this alignment. As such the information captured within the FIR will be non-technical and mainly focus on managerial and financial related information. environment. The workshop should be developed from such requirements engineering techniques including stakeholders' engagement, Joint Design Application (JDA), brainstorming and prototyping. Stakeholders' engagement should focus on highlighting the critical personnel required in the workshop. The FIR is vital in aligning the organisation with its engineered assets, as such the key personnel should understand the organisational management framework such as risk management, capital investment decisions and customer management processes. Typical personnel include asset managers, financial directors, risk managers and customer engagement managers. Due to the multidiscipline nature of this process using the user involvement nature of JDA to structure the workshop is

378 a natural fit. While there is no hard structure for the development of JDA workshops, there are some fundamental building blocks that include facilitation, agenda setting/structure, documentation and 
group dynamics. Brainstorming is a group creativity technique that aims to find a dynamic conclusion

381 to a set of problems. specifically, guided brainstorming is used as part of the group exercise within the

382 JDA and therefore in the development of FIR. Depending on the complexity of the organisational

383 objectives and the asset functions it could be beneficial to develop a set of prototypes, simulating the

384 use of the information requirements within the FIR workshops to support the decision-making

385 processes. The benefits are two-fold: firstly, it supports the validation that the development

386 information requirements are fit for purpose. Secondly, it limits the risk of an IMS being developed that

387 is not fit for purpose and requiring expensive upgrade and reworks. It is important to state that not all

388 prototypes have to be software development related, it can emulate an event happening and the

389 exchange of information within current business and software processes, therefore validating if the

390 correct information requirements have been captured for the associated organisational objective.

391 The final task in this step is to align the asset systems that support the asset functional output. As an

392 example, the function of heating can be supported by multiple asset systems such as a gas boiler

393 system, underfloor heating system and electric heating system. Asset manager, maintainer and

394 operators should be consulted to ensure that all the asset systems are captured. UNIClass

395 classification system table Ss provides a classification of 2083 asset system. Similarly, Omniclass

396 provides a classification of asset systems. These classification systems should be used as references

397 to ensure consistency.

398 To support the capture of the information requirements developed during the workshop, an

399 Information Requirements Matrix has been developed. The matric captures information within the

400 categories of managerial, technical and financial, which replicas the categories of questions develop

401 within the OIR (see step 3). Furthermore, the matric supports the alignment of the functional asset

402 output to asset systems. The matrix should be collaboratively completed within the above-described

403 workshop and used as a tool to document the developed information requirements. Figure 5,

404 illustrates an example of a completed Information Requirements Matric. 


\begin{tabular}{|c|c|c|c|}
\hline $\begin{array}{l}\text { Information } \\
\text { Requirements }\end{array}$ & \multicolumn{2}{|c|}{ Heating Functional Output } & Financial \\
\hline $\begin{array}{l}\text { Managerial } \\
\text { Information }\end{array}$ & $\begin{array}{l}\text { <maintainer> } \\
\text { <operator> } \\
\text { <client_owner> }\end{array}$ & $\begin{array}{l}<\text { name }> \\
<\text { function }> \\
<\text { location }>\end{array}$ & $\begin{array}{l}<\text { detailed_location }> \\
<\text { description }> \\
<\text { run_time }>\end{array}$ \\
\hline $\begin{array}{l}\text { Technical } \\
\text { Information }\end{array}$ & $\begin{array}{l}\text { <service_life> } \\
<\text { Remaining_life> } \\
\text { <current_performance> }\end{array}$ & $\begin{array}{l}\text { <historical_performance> } \\
\text { <optimise_performance> } \\
\text { < criticality_rating> }\end{array}$ & $\begin{array}{l}<\text { planned_maintenance }> \\
<\text { reactive_maintenance }>\end{array}$ \\
\hline $\begin{array}{l}\text { Financial } \\
\text { Information }\end{array}$ & $\begin{array}{l}\text { <operational_cost }> \\
<\text { total_maintenance_cost }> \\
<\text { whole-life_cost }>\end{array}$ & $\begin{array}{l}\text { hancial_owner> } \\
\text { rget_cost> } \\
\text { active_maintenance_cost> }\end{array}$ & $\begin{array}{l}\text { oactive_maintenance_cost }> \\
\text { al_cost> }\end{array}$ \\
\hline $\begin{array}{c}\text { Asset } \\
\text { Functions }\end{array}$ & Gas Heating System & $\begin{array}{c}\text { Electric Heating } \\
\text { System }\end{array}$ & $\begin{array}{c}\text { Hot Water Heating } \\
\text { System }\end{array}$ \\
\hline
\end{tabular}

407 the critical outcome of this step is a comprehensive set of FIR's that aligns to supporting asset

408 systems. The information requirements are developed within a collaborative workshop environment,

409 utilising elements of brainstorming and prototyping. While the information captured should be

410 comprehensive, it is worth noting that it should only focus on the information required at the functional

411 level of the asset and not the asset systems level, these will be captured in the following step. The

412 FIR should aim to provide answers to the questions that were raised in the developed of the OIR (step

413 3).

\section{Step 5 - Develop Asset Information Requirements (AIR)}

415 The fifth step is to develop the AIR for the asset systems that have been defined within the functional

416 information requirements matric. To avoid confusion with the associated BIM 1192 standards, this

417 step will develop asset information requirements as defined within the 1192 standards, both asset

418 systems and products information requirements are captured within the AIR. The definition of an AIR

419 is "any information that is captured at an assets system, sub-system or product level of an

420 organisations asset classification system that supports the organisational requirements for their

421 assets, including operational and maintenance management, spares management and risk

422 assessments". The AIR should aim to provide the data for the information requirements developed

423 within the FIR.

424 Much like the development of FIR, the development of AIR is best achieved in a multi-discipline

425 collaborative workshop environment. The workshop should utilise the same methodologies such as 
stakeholders' engagement, join design application and brainstorming. In addition to this, a new

427 dynamic group exercise is introduced called the Information Delivery Manual (IDM) $[44,45]$. While the

428 limitations of using the IDM methodology as a single solution for the development of information

429 requirements was expressed within section 1 , in the context on this framework and more specify this

430 step it provides a structured approach to the capture of AIR. Regarding stakeholders' engagement at

431 the AIR level, it is required to have the personnel that operate and maintain the asset portfolio at the

432 asset system and product level. As such, it is required to have operational and maintainer engineers

433 that have a strong technical understanding of how the assets within a system and as individual

434 assets.

435 The IDM methodology utilises process maps that are defined using Business Process Modelling

436 Notation (BPMN), specify the actions for a given activity and the supporting data and information

437 requirements that support the given activity. The IDM methodology is divided into three discrete parts

438 including process maps, exchange requirements and technical implementation. The IDM methodology

439 is used to capture the current (as-is) flow of information between the defined actors of an asset-

440 system for a given EAM activity. This process will capture the specific information that is exchanged

441 to support activities such as maintenance, commissioning of new assets and risk assessments. While

442 not all these activities will directly relate to an organisational objective, they will support in achieving

443 the objectives. As an example, the information captures the activity of maintenance will have an

444 impact on the objective to reduce business costs by $5 \%$. The information highlighted is analysed

445 within a workshop environment and If demanded appropriate to help answer a question or questions

446 developed within the OIR, it is captured within the information requirements matrix (see Figure 5) and

447 forms part of the AIR. The process map should be completed in a collaborative workshop

448 environment with stakeholder from the above stakeholders' engagement exercise. Firstly, an EAM

449 activity is selected, care should be taken to prioritise the key activities that will impact the

450 organisational objectives. Secondly, the actors are identified. These are actors that within some point

451 within the activity they send or receive information as part of the process, manually such as an email

452 or a phone call and automatically such as an automatic work order sheet or asset failure warning from

453 a sensor. These actors are structured into "swim lanes" which these swim lanes are the processes

454 and functions that the individual actors perform, these are indicated by rectangles and the flow by

455 solid arrows. A process map will always have the swim lane Exchange when information is 
exchanged between the actors it is highlighted within this swim lane and the flow of information by

457 long dotted arrows. The manual exchange of information is indicated by an envelope while the

458 automatic exchange is indicated by a sheet with a folded corner as per the IDM and BPMN standards.

459 As part of the BIM design model classification process, BS 1192 provides a standard set of roles

460 (actors) that should be used as guidance which defines such roles as a facility manager, contractor,

461 client, civil engineer, building surveyor and structural engineer [34]. Furthermore, UNIClass table

462 Project Management (PM) provides a classification of design, construction and EAM key roles and

463 actors [53]. The defined actors should be classified where possible to allows for future automatic data extraction and filtration per actor type. Figure 6, provides an exchange of a process map show the essential functions and processes within the actors' swim lanes and the exchange of information within the activity of asset failure.

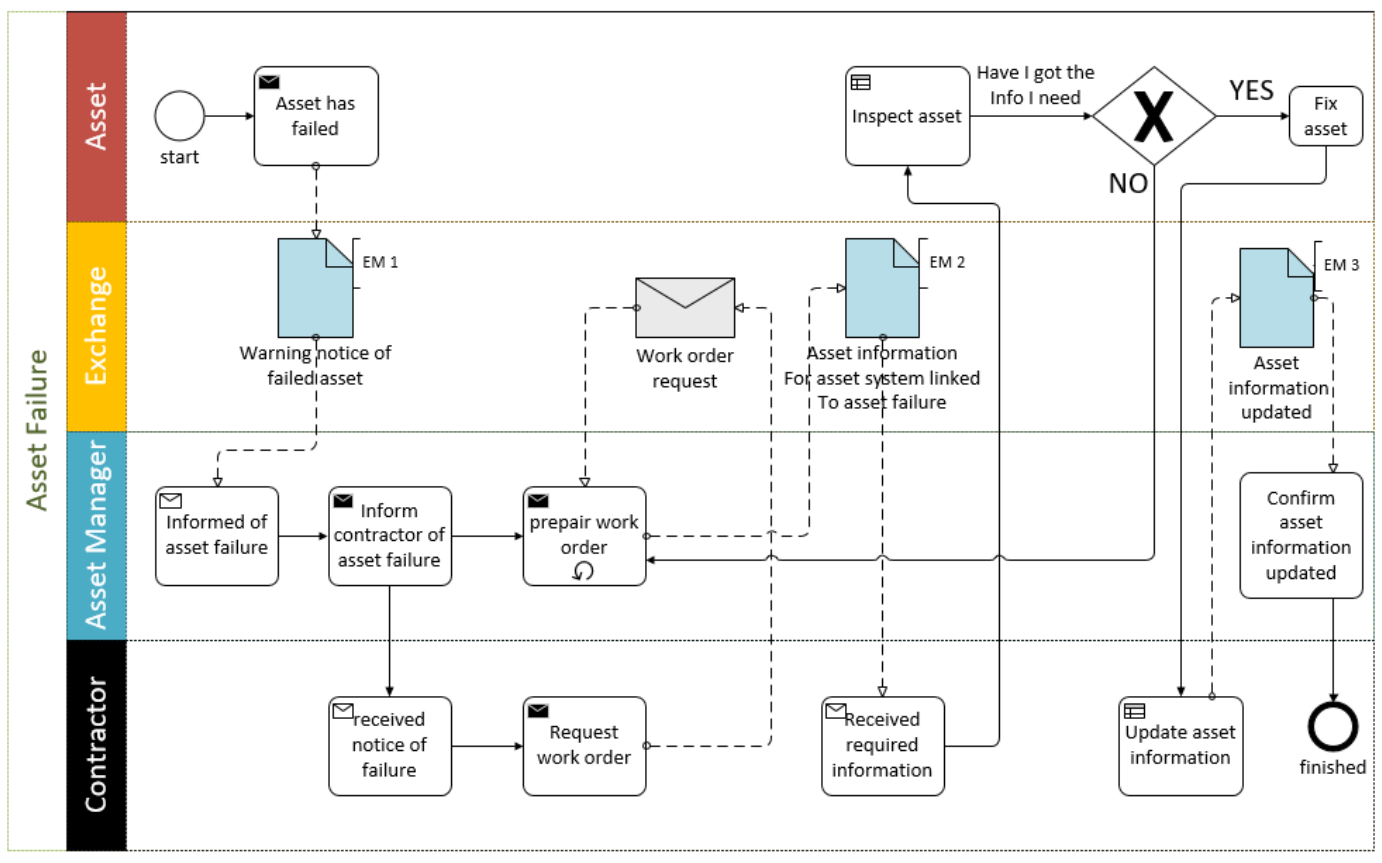

469 The final requirement of the IDM methodology is to develop exchange requirements (ER), these

470 indicate the specific information that is exchanged at a given time or after a function or process

471 between the actors. The ER should capture two elements of the exchange: firstly, the information unit

472 that is an exchange, including a description of the information unit and its use. Secondly, any

473 information constraints such as data types. 
474 The critical part of this step is to develop a comprehensive set of AIR. The main exercise in this step

475 is developing a set of process maps that identify the processes and functions for a given EAM activity

476 and highlights the information exchange between the given actors. The exercise is designed to

477 capture the current (as-is) flow and exchange of information, the developed ER are analysed within a

478 collaborative workshop environment and analysed on their capability to aid in answering the questions

479 developed within the OIR (Step 3), if they are deemed appropriate they are captured within the

480 information requirements matrix and form part of the AIR.

\section{Step 6 - Validate the developed information requirements}

482 the sixth step is to validate that the captured information requirements are fit for purpose and support

483 the line-of-sight required from the organisation objectives to the performance of the assets and

484 confirm if the objective is being achieved (or not). Furthermore, this step also confirms that the

485 information requirements captures are the correct ones needed and an adequate quantity has been

486 developed.

487 The validation process, much like the OIR, AIR and FIR developed should be completed within a

488 collaborative workshop environment, utilising the same methodology of JDA and stakeholders'

489 engagement. The validation process is complex in nature. Firstly, it requires diverse stakeholders with

490 often conflicting goals to reach an agreement [55]. Secondly, real validation of the information

491 requirements can only be achieved within their "real world" usage, which is often an expensive and

492 timely task.

493 addressing the first challenge, it is required to resolve the conflicts between the different stakeholders

494 without efficient the individual goals and requirements. Robison and Volko [56] propose a negotiation

495 project lifecycle model that incorporates the organisational point-of-view, by first setting out their goals

496 and objectives in the early stages of the negotiation, the overarching theme is a level and common

497 playing field where all participants are working towards a single set of goals and objectives. The

498 advantage of using this approach are two folds. Firstly, as part of this framework, we have already

499 established the organisational goals and objectives within step 1, there can be used as the

500 overarching goals of the negotiation process. Secondly, as described in section 2 one of the key

501 challenges within EAM is its multifunctional aspect that is often neglected within information

502 requirement development. The common playing field approach with common goals and objectives 
support the collaborative framework and environment that supports the required cross-functional negotiation processes

505 Addressing the second challenge, we utilise the same IDM methodology that was used within step 5, but this time focusing the developing process maps that show the to-be (future) processes and exchange of information and not the as-is (current). The process maps are developed within the same steps but solely focused on the newly developed information requirements. The focus should be given to ensuring that the information exchange is efficient in meeting the OIR and ultimately the organisational objectives. It might be found in this step that new organisational processes need to be developed to support information exchange. As an example, notifying the financial department of any unscheduled asset renewal costs before the commissioning of the asset. The process maps to aid in validating that all the information requirements are fit-for-purpose by analysing the flow of information

514 within EAM activities. Furthermore, utilising IDM process maps allows for a quick, comprehensive and easy validation process, without having to develop complex and expensive IMS for testing.

516 The critical outcome of this step is a comprehensive set of negotiated and validated set of information requirements. The organisational requirements, OIR, FIR and AIR should be validated. As stated the

518 OIR is developed at the organisational functions level, as such, the clear majority of these requirements will be managerial and financial related. Therefore, the appropriate stakeholder who understands these functions should validate the OIR. furthermore, the FIR and AIR are more technical related and therefore require more technical stakeholders to validate their requirements.

\section{Step 7 - Document and communicate the developed information requirements}

523 The seventh and final step of this framework is the need to document and communicate the information requirements, this includes documenting the output of the classification of organisational objectives (step 1), asset classification (step 2), OIR (step 3), FIR (step 4) and AIR (step 5). categorised, the name of the document extracted from and finishing timeline of the objective. The objectives should be easily accessible by both the management team and maintain / operational teams. Care should be taken to ensure that the format of the objectives is not overly complicated and is easily understandable by the whole organisation. 
531 Regarding the asset classification system (step 2), the classification of individual asset functions,

532 systems and products should be documented. Furthermore, the parent-child relationship between the

533 asset function, systems and products (see Figure 4) should be documented. The asset classification

534 should be captured as part of an asset register, which then supports efficient data filtering, extraction

535 and exploitation. The database of the asset classification its self should be stored in a relational

536 database which is widely accessible to the organisation such as Structured Query Language (SQL),

537 Microsoft Access or Excel. The classification database should be used as a reference for the

538 development of an asset register and classification of objects within BIM design models.

539 Building on the documentation of the objectives and asset classification, it is then possible to start

540 documenting the developed information requirements (OIR, FIR and AIR). The OIR is captured as per

541 Table 3 within step 3 . Along-side the information requirements, other identifying information is

542 captured as Critical Success Factor, categories, plain language questions and data types. It is critical

543 that the information requirements themselves are accessible, as they will support the development of

544 the FIR and AIR. When documenting the FIR, we utilise the Information Requirements Matrix (see

545 Figure 5), this allows for the alignment of the OIR and the asset functions. A pivotal step to

546 documents within the FIR process is the top 3 to 5 asset functions that impact the Organisational

547 Objective, an Information Requirements Matrix is developer per each highlighted function, which

548 therefore develop the FIR. As within the development of the OIR, it is critical that the information

549 requirements captured within the FIR process are accessible as they support the development of the

550 AIR. AIR also utilise the Information Requirements Matric to store the identified information

551 requirements.

5524 Case Study

553 This section aims to demonstrate the practical applicability of the methodology by applying

554 this in two case studies - the Estate Management department for a university and a major

555 city public transport provider. A brief overview of the approach taken for the case studies is

556 provided first, and a summary of feedback, lessons learnt and challenges within

557 methodology implementation is provided at the end of this section. 


\subsection{Case Study Approach}

561 Initially, one to one interviews with structured and unstructured questions were conducted to

562 ensure the organisation has the appropriate documentation, resources and skills to

563 participate within the case study. The case studies followed the same steps as outlined in

564 Figure 3. As discussed within step 3, the case studies were developed utilising JDA. In total

565 two OIR workshops per case study where completed involving 4 to 6 personnel from senior

566 management positions from the departments of financial management, resource

567 management, customers management, O\&M management and the asset management

568 teams. Both the FIR and AIR workshops involved 5-10 technical and operational personnel

569 from the maintenance response team, maintenance planners, spares management,

570 procurement and invoicing, customer engagement teams and quality controls. Two

571 workshops each for FIR and AIR were carried out per case study. Excel-based templates

572 were developed that provide a constrained and structured approach to data capture. After

573 each workshop, the data was analysed with a summary and feedback provided to the

574 organisation within an informal meeting.

575 Feedback on the results of the case study was obtained by interviewing personnel within the

576 organisation to validate that the information captured using the process aided in supporting

577 their strategic needs. Further validation was achieved by witnessing (or through feedback)

578 the organisation being able to make greater informed decisions within their asset

579 management system.

580

$581 \quad 4.2$ Methodology Review

582 The Estate Management team provides all of the university's O\&M requirements while managing the

583 financial costs, planning and scheduling of works and commencing of new assets / buildings.

584 Furthermore, Estate Management also manages the IT applications that are used to support asset

585 management activities such as capturing maintenance reports. Historically the Estate Management

586 team has struggled to report efficiently on their assets' performance (financial and non-financial) and 
587 are often focused on acting reactively. This is partly due to poor information management.

588 Specifically, Estate Management had not implemented a standard asset classification system or used

589 a structured approach to the development of AIR, which means they struggle to filter and extract the

590 data that meets their requirements. Recently Estate Management embarked on a transformation

591 process that includes adopting asset management and BIM. As part of this transformation we have

592 implemented the methodology presented in this paper to support their information requirements

593 development. The newly developed Strategic Asset Management Plan (SAMP) was exploited and 18

594 objectives were extracted. This included financial (reduce operational costs), environmental (reduce

595 environmental impact) and operational (less reactive and more predictive maintenance) objectives.

596 Furthermore, the broader university strategies were utilised to obtain high-level customer and

597 reputational objectives. Secondly, their current asset register was reviewed and the assets were

598 classified into functional outputs and asset systems using the UNICLass classification. This was

599 validated by interviews with key personnel in the Estates Management team. In total, 42 functions

600 were classified with their associated asset systems. OIR's where developed within collaborative

601 workshops that saw CSFs and PLQs being developed for each individual objective. On average 4

602 CSFs where developed her objective and 15 PLQ. Finally, the FIR and AIR were developed utilising

603 the newly created asset classification system and working within collaborative workshops, with the

604 correct stakeholders both at the FIR and the AIR level. Developing the FIR helped to bridge the gap

605 between the OIR and the AIR, allowing non-technical management to engage with the process at a

606 level that was understandable and were able to articulate their requirements.

607 The public transport provider case study is currently in its initial stages and is significantly larger then

608 Estate Management. This organisation maintains and operates all of the roads, rail, bus and metro

609 within a major city. One of the first challenges for this organisation was extracting and organising the

610 objectives as they were spread over several documents including Balance Scorecards, environmental

611 frameworks, business plans, SAMP and customer engagement policy. In whole 87 unique objectives

612 where identified. This exercise identified overlapping and conflict objectives within the broader

613 organisation that could be addressed and consolidated as needed. As the organisation already has a

614 comprehensive asset classification system, it was only required to classify the functional outputs and

615 develop the relationships between the already classified asset systems. At this stage, we are currently

616 in the process of developing OIR and FIR. 
617 From these case studies, it could be seen that a structured methodology for the development of OIR

618 and AIR allows organisations to effectively develop information requirements that meet their

619 requirements. Both organisations had some kind of AIRs developed within their asset management

620 tools, but they were often developed in an ad-hoc manner and only focused on the technical

621 requirements. Furthermore, both organisations did not have a single OIR document. While some of

622 these requirements would be in their management processes, they were poorly documented and

623 often misunderstood. Moreover, there was a clear challenge in how to translate often abstract and

624 high-level OIR into AIR.

625 Following this approach allowed the organisations to focus on their high-level requirements (OIR) and 626 to be translated into AIR. The FIR acted as an effective stepping stone to translate from OIR to the

627 AIR. The easily understandable nature of functional outputs aided non-technical personnel to be able

628 to engage in the process and have their requirements captured.

\section{$629 \quad 4.3$ Lessons Learnt}

630 While the methodology as a whole supports the development of AIR, the processes and

631 tools used within the methodology are not without their own challenges. Stakeholder

632 engagement and selection was critical to ensure the correct personnel were in the

633 workshops. It was often a challenge to ensure that the appropriate personnel were in the

634 different workshops to support the development of specific information requirements. The

635 case studies revealed that the development of IDM during the AIR workshop can often

636 create conflicting process maps and highlight multiple workflows for the same action. This

637 can result in challenges within the negotiation process for prioritising the workflows. Finally,

638 while the methodology was generally accepted as useful and generated the results that were

639 valuable to the asset managers, it was noted that organisational departments that are not

640 typically associated with asset management would require extra support throughout the

641 processes. It was also noted that further work is perhaps necessary to ensure that the

642 methodology can be used by practitioners at large without support from the authors. 
645 this paper proposed an organisational lead asset information requirements development process that

646 is guided by the traditional concept of engineering requirements and the emerging domain of BIM.

647 The literature review (within section 2) discovered that the development of information requirements is 648 a complex and often puzzling task. The earliest development of IMS within the 1960/70's often

649 neglected the task of information requirements development and result in reduced operational

650 perf=ormance. Furthermore, the adoption of IMS within EAM is immature compared to other domains.

651 While a branch of software engineering called Requirements Engineering (RE) has provided a

652 framework for the development of information requirements, the standard techniques used within the

653 framework have limited use within EAM due to its multifaceted nature. BIM has been described as an

654 enabler for the adoption of an IMS within the construction and EAM sectors. While BIM has been

655 actively implemented within the design and construction phases, it is adoption within the operational

656 phase has been limited. This is partly due to the complexity of capturing OIR within the initial stages

657 of the BIM information management processes. While there are a few example methodologies within

658 the reviewed literature, they fail to create the required alignment between the OIR and the AIR and

659 therefore do not address the BIM requirements. There is a definite requirement for the development of 660 new techniques that build of the work completed within RE and accompanies the emerging domain of

661 BIM and EAM.

662 Section 3, firstly, recommends an extension to the current BIM information management relationships 663 (see Figure 2), this involves aligning high-level EAM documentation such as organisational policies, 664 objectives and plans to the OIR. This provides a direct link between the organisational documentation 665 and the development of the OIR. It was witnessed that the link between the OIR and the AIR was too 666 much of a leap for EAM organisations and a new set of information requirements to support the OIR 667 generating the AIR, which takes advantage of the organisational point-of-view of their assets as the 668 functional output they support and proposed Functional Information Requirements (FIR). Step 1 669 involves reviewing organisational documentation, specifically EAM related and extract objectives from 670 the documentation. Once the objectives have been extracted, they are then categories by operational, 671 environmental, health \& safety, financial and reputational. Step 2 requires the organisation to classify 672 their engineering assets as per the functional output they support and the asset systems that support 
673 that function, with a parent-child relationship. Step 3 is the development of OIR, a set of OIR's are

674 developed per objective extracted within step 1. Step 4 is using the functions that were classified

675 within step 1 and the OIR developed within step 3 to develop the FIR. Each function is put within the

676 Information Requirements Matrix (see Figure 5) and information requirements are captured under the

677 categories of technical, managerial and financial. Step 5 is the development of AIR, the critical feature

678 of the AIR development is completing an AS-IS (current) IDM process map, to capture the points of

679 exchange and the information exchanged. step 6 aims to validate the created information

680 requirements. This is achieved in a collaborative workshop environment that supports the negotiation

681 process to allow conflicting and often diverse stakeholders to agree on the information requirements.

682 Step 7 is the final set to document all the created information requirements. All documentation should

683 be both human readable and machine readable, machine-readable aspect is out of the scope of this

684 paper. Any parent-child relationships, such as those developed within asset classification should be

685 maintained.

686 Traditionally AIR our generated from the bottom-up, meaning they are more technical operational

687 requirements, as maintenance and operational personnel have developed them for their own

688 requirements. This means that organisational financial, environmental and reputational requirements

689 are often missed within the AIR. The proposed framework provides a direct alignment between the

690 organisation objectives and the information that is captured at an asset level. This is achieved by

691 directly developing OIR from the organisation objectives that generate the AIR via FIR. This has

692 several advantages. Firstly, it supports the capture of organisational requirements at the asset level.

693 Secondly, it means that only information that is relevant to the organisation is captured. finally, it

694 provides a structured and repeatable framework, no matter the sector or industry.

695 Future research should focus on how the structure of the captured information in the sense of

696 technical development. This should include elements of how the information is stored, in what format

697 and how information is exchanged between the different stakeholders' and lifecycle phases.

698 Furthermore, to the dynamic nature of organisational objectives and the manual task of extracting

699 them within step 1, future research should investigate how emerging technology can support

700 organisations to digitalise their organisational documentation and streamline this step.

\section{$701 \quad$ Acknowledgement}



and Costain Plc through an Industrial CASE Award. The authors also thank the support of the EPSRC Innovation and Knowledge Centre for Smart Infrastructure and Construction as well as the Centre for Digital Built Britain.

\section{Reference}

707 [1] ISO, ISO 55000:2014 Asset Management -- Overview, principles and terminology, 2014.

708 [2] ISO, ISO 55001 - Management System - Requirements, 2014.

709 [3] ISO, ISO 55002 - Management System - Guidelines for application of ISO 55001, 2014.

710 [4] RIBA Enterprises, National BIM Report, (2017) 1-28. doi:10.1017/CBO9781107415324.004.

711 [5] S. Azhar, Building Information Modeling (BIM): Trends, Benefits, Risks, and Challenges for the AEC Industry, Leadership and Management in Engineering. 11 (2011) 241-252. doi:10.1061/(ASCE)LM.1943-5630.0000127.

714 [6] D. Bryde, M. Broquetas, J.M. Volm, The project benefits of Building Information Modelling (BIM), International Journal of Project. 31 (2014) 971-980. doi:10.1016/j.ijproman.2012.12.001. review and a case study investigating the value and challenges, 13th International Conference Applications of Virtual Reality. (2013) 30-31. http://itc.scix.net/data/works/att/convr-201320.pdf.

B. Becerik-Gerber, F. Jazizadeh, N. Li, Application areas and data requirements for BIMenabled facilities management, Journal of Construction Engineering and Management. 138 (2011) 431-442. doi:10.1061/(ASCE)CO.1943-7862.0000433. Industrial Informatics. 7 (2011) 630-640. doi:10.1109/TII.2011.2167156. interoperability in the field of 3D measurement data management, Journal of Industrial Information Integration. 12 (2018) 47-56. doi:10.1016/j.ji.2018.01.006. and cyber-physical systems, Journal of Industrial Information Integration. 9 (2018) 14-23. doi:10.1016/j.jii.2017.12.001. 
[13] S. Ashworth, M. Tucker, C. Druhmann, M. Kassem, Integration of FM expertise and end user needs in the BIM process using the Employer's Information Requirements (EIR) Integration of FM expertise and end user needs in Requirements (EIR), Conference: European Facilities Management Conference. (2016). doi:10.1364/OE.18.023664.

739

[14] British Standards Institute, PAS 1192-3:2014 Specification for information management for the operational phase of assets using building information modelling, 2014. https://bimlevel2.org/en/standards/.

742

[15] J.C. Wetherbe, Executive Information Requirements: Getting It Right., MIS Quarterly. 15 (1991) 51-65. doi:10.2307/249435.

[16] R.L. Ackoff, Management Misinformation Systems, Management Science. 14 (1967) 147-156. doi:10.1287/mnsc.14.4.B147.

[17] A.M. Jenkins, J.D. Naumann, J.C. Wetherbe, Empirical investigation of systems development practices and results, Information and Management. 7 (1984) 73-82. doi:10.1016/03787206(84)90012-0.

[18] N.M. Bonanno, P.K. Poddutoori, K. Sato, K. Sugisaki, T. Takui, A.J. Lough, M.T. Lemaire, SOFTWARE REQUIREMENTS: ARE THEY REALLY A PROBLEM?, Chemistry - A European Journal. 24 (2018) 14906-14910. doi:10.1002/chem.201802204.

752

[19] J.A. Zachman, Business Systems Planning and Business Information Control Study: A comparison, IBM Systems Journal. 21 (1982) 31-53. doi:10.1147/sj.211.0031.

[20] J.F. Rockart, Chief executives define their own data needs., Harvard Business Review. 57 (1979) 81-93. https://hbr.org/1979/03/chief-executives-define-their-own-data-needs.

[21] J.C. Wetherbe, G.B. Davis, Developing a Long-range Information Architecture, Proceedings of 757 the May 16-19, 1983, National Computer Conference. (1983) 261-269.

759 doi:10.1145/1500676.1500709.

[22] M. Maguire, N. Bevan, User requirements analysis: A review of supporting methods, Proceedings of IFIP 17th World Computer Congres. (2002) 133-148. doi:10.1007/978-0-38735610-5_9.

[23] P. Zave, Classification of research efforts in requirements engineering, ACM Computing Surveys. 29 (1997) 315-321. doi:10.1145/267580.267581. Publishing, 1998. doi:10.1139/apnm-2013-0071. 
resource management, Journal of Environmental Management. 90 (2009) 1933-1949. doi:10.1016/j.jenvman.2009.01.001.

[26] T.L. Saaty, Decision making with the analytic hierarchy process, International Journal of Services Sciences. 1 (2008) 83. doi:10.1504/IJSSCI.2008.017590.

[27] S.J. Andriole, Storyboard Prototyping: A New Approach to User Requirements Analysis, QED Information Sciences, Inc., Wellesley, MA, USA, 1989.

[28] K.D. Eason, Information Technology and Organisational Change, (1988) 247. doi:https://doi.org/10.1177/103841119002800210.

776

[29] The Institute of Asset Management, PAS 55-1-2004, British Standard Institution. (2004) 24.

[30] The Institute of Asset Management, PAS 55-2:2004, British Standards Institution. (2004) 1-72.

778

[31] J.E. Amadi-Echendu, R. Willett, K. Brown, T. Hope, J. Lee, J. Mathew, N. Vyas, B.S. Yang, What is engineering asset management?, Engineering Asset Management Review. 2 (2007) 116-129. doi:10.1007/978-1-84996-178-3_1.

781

[32] E.A. Pärn, D.J. Edwards, M.C.P. Sing, The building information modelling trajectory in facilities management: A review, Automation in Construction. 75 (2017) 45-55.

783 doi:10.1016/j.autcon.2016.12.003.

784

[33] British Standards Institute, PAS 1192-2 Specification for information management for the capital/delivery phase of construction projects using building information modelling, 2013. https://bim-level2.org/en/standards/.

[34] British Standards Institute, BS 1192-2007+A22016: Collaborative production of architectural, engineering and construction information, (2007). https://bim-level2.org/en/standards/.

[35] British Standards Institute, BS 1192-4:2014 Collaborative production of information Part 4: Fulfilling employer' $s$ information exchange requirements using COBie - Code of practice, British Standards Institute. (2014) 58. https://bim-level2.org/en/standards/.

[37] British Standards Institute, PAS 1192-6:2018 Specification for collaborative sharing and use of structured hazard and risk information for Health and Safety, (2017). https://bimlevel2.org/en/standards/.

[38] A. Koteja, M. Szczerba, J. Matusik, Smectites intercalated with azobenzene and aminoazobenzene: Structure changes at nanoscale induced by UV light, Journal of Physics

801 [39] S. Ashworth, M. Tucker, C. Druhmann, The Role of FM in Preparing a BIM Strategy and 

Employer's Information Requirements (EIR) to Align with Client Asset Management Strategy, 15th EuroFM Research Symposium. (2016) 8-9.

[40] J.M. Kamara, C.J. Anumba, N.F.O. Evbuomwan, I.C.E. Publishing, T. Crpm, T. Jfet, L.F. Epstein, I.C.E. Publishing, R. Analysis, C. Factors, Capturing Client Requirements in Construction Projects, Most. (2002) 173. doi:10.1016/j.rser.2013.12.007.

[41] H.B. Cavka, S. Staub-french, E.A. Poirier, Automation in Construction Developing owner information requirements for BIM-enabled project delivery and asset management, Automation in Construction. 83 (2017) 169-183. doi:10.1016/j.autcon.2017.08.006.

[42] J. Patacas, N. Dawood, D. Greenwood, M. Kassem, Supporting building owners and facility managers in the validation and visualisation of asset information models (aim) through open standards and open technologies, Journal of Information Technology in Construction. 21 (2016) 434-455.

[43] buildingSMART alliance, buildingSMART - The Home of BIM, (n.d.). https://www.buildingsmart.org/ (accessed October 10, 2018).

[44] ISO, BS ISO 29481-1:2016 - Building Information Modelling - Information Delivery Manual, 1 (2010) 60.

[45] ISO, BS ISO 29481-2:2016 - Building Information Modelling - Information Delivery Manual, (2016).

[46] ISO, BS ISO 12006-2:2015 Building construction Organization of information about construction works Part 2: Framework for classification, (2015).

[47] ISO TC 59/SC 13, ISO 12006-3:2007 Building construction - Organization of information about construction works, 2007.

[48] British Standards Institution, BS 8536-1-2015_Briefing for design and construction - Part 1 : Code of practice for facilities management (Buildings infrastructure), 2015. https://bimlevel2.org/en/standards/.

[49] British Standards Institution, BS 8536-2:2016 Design and construction : Code of practice for asset management (Linear and geographical infrastructure), 2016. https://bimlevel2.org/en/standards/.

[50] Cabinet Office, Government Soft Landings, 2013. http://www.ecobuild.co.uk/files/bp_5_mar_12.30_deborah_rowland.pdf.

[51] ISO, ISO/TC 59/SC 13, (n.d.). https://www.iso.org/committee/49180.html (accessed September 10, 2018).

[52] G. Lawrie, I. Cobbold, Third-generation balanced scorecard: evolution of an effective strategic control tool, International Journal of Productivity and Performance Management. 53 (2004) 
837 [53] S. Delany, UNICLASS Calssification, NBS. (2015).

838 https://toolkit.thenbs.com/articles/classification (accessed November 15, 2016).

839 [54] OCCS, Omniclass, (2017). http://www.omniclass.org/ (accessed February 22, 2018).

840 [55] B. Nuseibeh, S. Easterbrook, Requirements engineering: A Roadmap, Proceedings of the 841 Conference on The Future of Software Engineering - ICSE '00. 1 (2000) 35-46.

842 doi:10.1145/336512.336523.

843 [56] W.N. Robinson, V. Volkov, Supporting the Negotiation Life Cycle, Communication of The $844 \quad$ ACM. 41 (1998) 95-102. doi:10.3109/13682822.2010.507616.

845 [57] Z. Zainal, Case study as a research method, 2007. http://psyking.net/htmlobj$8463837 /$ case_study_as_a_research_method.pdf (accessed February 27, 2019). 